\title{
Standardization Efficiency Variability Index Model of Supply Logistics Systems for Automobile Parts
}

\author{
Huishu Piao ${ }^{1, *}$, Jing Wang ${ }^{2}, \mathrm{Xia} \mathrm{Li}^{1}$, Jinfeng Chen ${ }^{1}$ \\ ${ }^{1}$ Transportation Management College, Dalian Maritime University, Dalian 116026, China \\ ${ }^{2}$ China Waterborne Transport Research Institute, Beijing 100088, China \\ ${ }^{*}$ Corresponding author
}

\begin{abstract}
For effectively measuring logistics standardization effect to promote the logistics standardization, it was proposed that logistics standards system and two kinds of "push" and "pull” logistics standardization modes based on supply logistics system architecture of automobile parts. Based on defining the logistics standardization composite index and its measurement method, using Malmquist index theory, it was decomposed that standardization efficiency variability index model of supply logistics system of automobile parts. Using the model and choosing the logistics standardization composite index, capital input, labor input, customer satisfaction degree index as input/output indicators, the supply logistics system efficiency and standardization efficiency were evaluated for six automobile assembly lines, and the evaluate results analyzed comparatively with the actual supply logistics operations of six lines to verify the availability of the logistics standardization efficiency variability index model.
\end{abstract}

Keywords-logistics system; standardization efficiency; Malmquist index; standardization mode

\section{INTRODUCTION}

As the most basic means of reducing the cost and increasing the efficiency, standardization of supply logistics systems for automobile parts attracted wide attention in logistics industry [1]. However, due to the complexity of supply logistics resulted from the bulky and diversity of parts required by automobiles as well as the lack of relevant theory research findings of logistics standardization, the current status of logistics standardization in this field is still not satisfactory, which results in higher costs for supply logistics of automobile parts in China [2]. Aim to make logistics standardization effective so as to guide supply logistics systems of automobile parts gradually towards lower cost and higher efficiency, from the perspective of architecture of supply logistics systems and the logistics standardization requirements for automobile parts, this paper explored the logistics standards system of supply logistics systems for automobile parts and established the Malmquist productivity index as well as its standardization efficiency variability index decomposition model of supply logistics systems for automobile parts by aid of DEA Malmquist theory and method. The effectiveness of the proposed model was verified by using an example, which provided a new methodology for standardization work of supply logistics systems for automobile parts in China.

\section{LITERATURE REVIEW}

Throughout the existing research literatures about logistics standardization and its effect on logistics system efficiency, they are divided into three fields: first field is that the importance and problems of logistics standardization were studied. For this field, there were a lot of relevant literatures (especially in China), but most of the literatures were only limited in doing qualitative research. There were several representative literatures among them. In terms of problems brought from standardization of a roll-rack of supply chain logistics for milk in Norway, Jahre ect.[3] explained the influence on boundaries delimitation of logistics systems and logistics standardization work for improving logistics system efficiency resulted from extension of research scope for logistics which is from the chain to the net, and proposed that the trade-off between " the current adaptation and future adaption ability" should be balanced well for developing logistics standards, but no further to study how to balance. Based on making clear the importance, advantages and disadvantages of standardization in logistics network, Nathalie[4] analyzed the interaction relationship between logistics standards and interaction relationship between logistics standards and other logistics resources by aid of the example of logistics standardization for automobile industry, then draw the conclusion that the standards are basic elements that gets the varies logistics resources in logistics network effectively integrate together. The literature also suggested that more application for logistics standards, more efficiency for logistics systems, however, the more easily it can hinder the development of logistics technology, finally concluded that how to balance the antinomy relationship of logistics standardization is a key research topic in the field of logistics standardization. Ciliberti[5] took 83 companies in Italy that met a certain requirement as the research objects, based on counting the practices adapted by 83 companies in such as purchasing social responsibility, sustainable transportation, sustainable packaging, sustainable warehousing and reverse logistics, and analyzed that the impact on society, economics and environment was brought from practices for different logistics areas of enterprises, and each practice' share and practice adoption index. The purpose of the research is to refine the relevant standard clauses that enterprises should follow for fulfilling the logistics social responsibility, and to provide the basis for standard setting of logistics social responsibility.

Second field is that the logistics standard system was studied. In this field, there are several representative articles, 
such as Piao Huishu[6] proposed logistics standard system based on logistics system structure, and the standard system is consistent with China's current logistics standard system table. On the basis of analyzing current status and existing problems of logistics standard system for China-Asean free trade zone, $\mathrm{Wu}$ Yanfeng[7] proposed the suggestion to set up the China-Asean standard and quality negotiation committee and pointed out that based on the logistics standard system of China, drawing from the strength of the standards of the each country in Asean was the best choice in establishing the logistics standard system of the China-Asean free trade zone. Wang Huixin[1] took supply logistics system of an automobile parts as an example, and put forward the standard system table of the third party automobile logistics.

Third field is that logistics efficiency and its evaluation methods were studied. In this field, there were many articles, which include from the researches about defining[8], importance[9] and measurement[10] of the logistics efficiency, researches[11] about method for improving the logistics efficiency to researches of evaluating the national macro-logistics efficiency[12] and third party logistics operation efficiency[13-14]. Among them, Tian Gang[12] took efficiency theory and productivity theory as the analytical framework, and utilized DEA method, statistical indicators method and SFA one-step method, from the angle of logistics systems, and analyzed the contribution approach of logistics technical efficiency and the technical progress for the sustainable development of regional logistics, and further from the point of view of region comparison, through empirical research, fully revealed the evolution process, regional characteristics and existing problems of the technical efficiency and technical progress of the logistics industry in China, and provided a theoretical basis and the new policy ideas for promoting the sustainable, coordinated development of regional logistics. Travel Min, etc.[13] took six third-party logistics companies in the United States (in the top 10) as an example, on the basis of calculating logistics operational efficiency of each enterprise, using DEA method, analyzed the correlation between the operational efficiency and enterprise operational income, net profit, resource utilization and competition performance index and the warning reflected from information of operational efficiency for management, thus verified that the DEA efficiency value takes an important role in analyzing relative competitiveness between homogeneous systems or enterprises and identifying the weakness of their respective management. Amer Hamdan, etc.[14] took 19 warehousing enterprises operated by the third party logistics companies in the United States as an example, on the basis of traditional DEA model with non-weighted constraints, further put forward improved DEA model with weight constraints based on the expert evaluation and enterprises' goal, and made a comparative analysis between evaluation results derived from improved model and the results derived from current evaluation tool based on key performance indicators, and the analysis results verified the effectiveness of the improved DEA model.

In short, there are many researches that do qualitative study on importance of logistics standardization and use DEA method to evaluate the logistics system efficiency, but literatures which link logistics standardization to logistics system efficiency and do quantitative analysis about correlation between logistics standardization and logistics system efficiency have not been found.

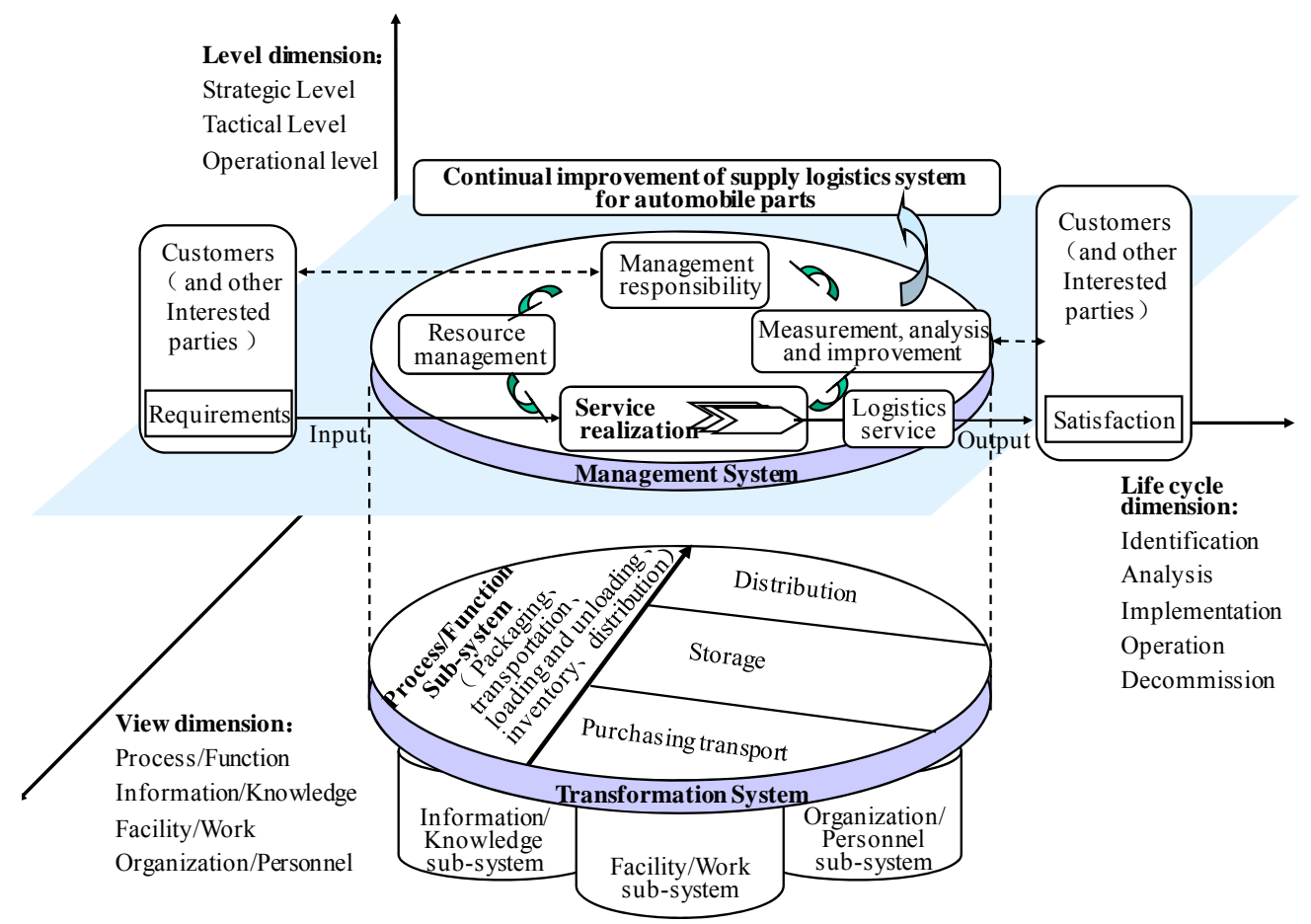

FIGURE I. ARCHITECTURE OF SUPPLY LOGISTICS SYSTEMS FOR AUTOMOBILE PARTS 


\section{Supply Logistics System OF Automobile Parts AND ITS STANDARDIZATION MODEL}

Logistics standardization is based on logistics standards. Logistics standards both taken from the logistics systems and service for the logistics systems, and its standard system is closely related to the structure of logistics systems.

\section{A. Architecture of Supply Logistics Systems for Automobile Parts}

Supply logistics of automobile parts is a complex system. It is a task for supply logistics systems to convey large and bulky parts required to the side of the production lines from over a hundred vendors in accordance with automobile production plans and on-line time requirements and to ensure the production process steady, orderly and efficient. It is a running target that at the right time delivering right quantity and varieties of right parts to the right place (that is, demanding point of all kinds of parts) in the right way, and at the same time, in pursuit of the lowest cost. Based on the research results of literature[6], architecture of supply logistics systems for automobile parts is shown in Figure.1. In terms of supply logistics systems for automobile parts, the process/function subsystem is at the core of the whole system, mainly including three links consisting of purchasing transportation, storage and distribution within organization or enterprises and five functions consisting of packaging, transportation, loading and unloading, storage, distribution. It is the main task of other subsystems how to obtain effective coordination between the three links and five functions so as to meet the requirement of automobile assembly, at the same time to make the whole system reduce the cost and increase the efficiency. As the fundamental of management, standardization becomes the most basic mean of prompting effective coordination between subsystems each other to realize the aim of reducing the cost and increasing the efficiency of the whole system.

\section{B. Standard System of Supply Logistics for Automobile Parts and Standardization Model}

In terms of supply logistics systems of automobile parts that collected tens of thousands of parts produced in different locations to the same production line, the importance of standardization is no doubt. It is the key that based on what standards how to standardize. It is first step to identify the required logistics standards and their system that benefit supply logistics systems of auto parts for reducing cost and improving efficiency. From the angle of the logistics standards that results from logistics systems and services for logistics systems, logistics standard system should be consistent with the architecture of the logistics systems. According to the architecture in Fig.1, Fig.2 shows the framework of supply logistics standard system for auto parts.

Based on the framework in Figure.2, developing effective and appropriate logistics standards is the target of supply logistics standardization for automobile parts. However, logistics systems are not immutable but dynamic systems changing continuously with market environment. How to seek a balance between variability of logistics systems and stability required by standardization is the biggest difficulty faced by the logistics standardization. Here, it is difficult point to identify the standards which need to be standardized within international range, the standards which need to be standardized within domestic range and the standards which need to be standardized within enterprise range.

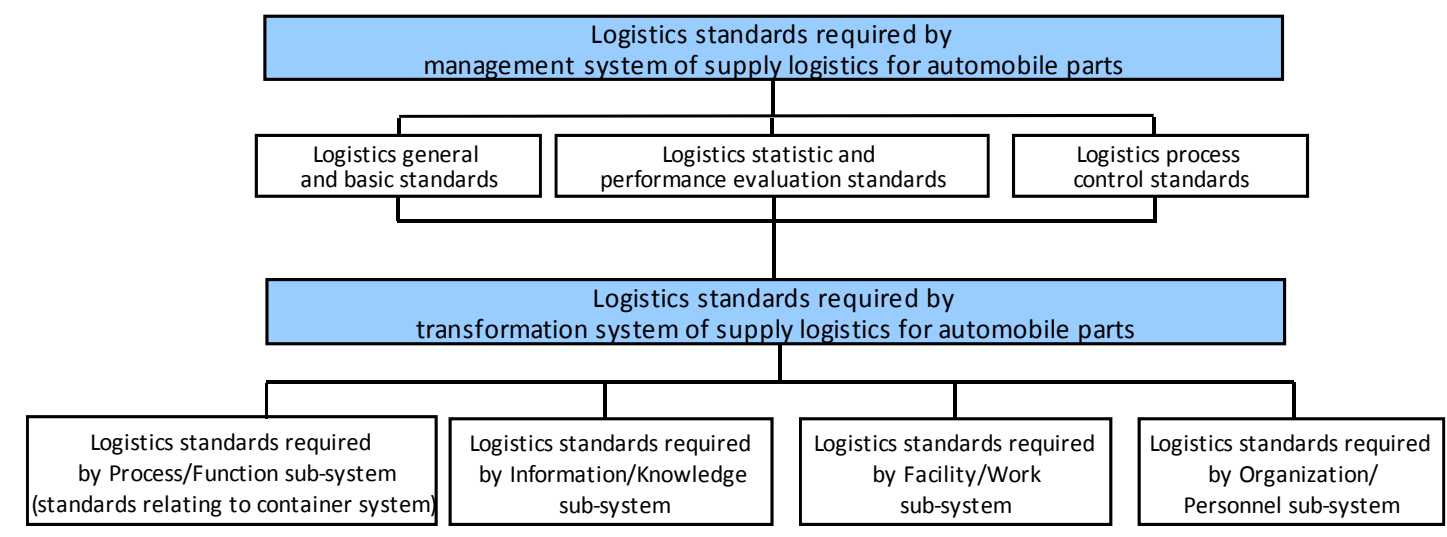

FIGURE II. FRAMEWORK OF SUPPLY LOGISTICS STANDARD SYSTEM FOR AUTOMOBILE PARTS

\section{Supply Logistics Standardization Mode for Auto Parts}

In view of wide range of application and high degree of complexity of supply logistics for auto parts, and there is a bigger gap for technology and management level between enterprises each other, supply logistics standardization of auto parts can be advanced with two kinds of modes in parallel. Among them, one mode is "push" logistics standardization which gives priority to standardization bodies, through four links such as identifying standard requirements, developing and setting standards, popularizing and applying of standards and assessment of standardization effect to pursue standardization. Another mode is "pull" logistics standardization which gives priority to standard users, through identification, application and evaluating varies standards to spread effective logistics standards which are suitable for the enterprises gradually so as to realize standardization. "Push" logistics standardization focus on cost reduction and more efficiency of logistics systems for macro industries, and "pull" logistics standardization focus on cost reduction and more efficiency of logistics systems for micro enterprises. That two modes are 
advanced in parallel brings about that the standardization scope of standards will be determined self-organizationally by market according to the standardization effect, and the standards will be popularized and applied.

So logistics standardization effect namely degree of logistics standardization impacting on the logistics system efficiency, however, should how to be measured. Using efficiency theory, this paper studied the measuring approach of standardization effect of supply logistics systems for auto parts.

\section{MALMQUiST INDEX AND STANDARDIZATION EFFICIENCY OF SUPPLY LOGISTICS SYSTEMS FOR AUTO PARTS}

\section{A. Malmquist Index and Standardization Efficiency Variability Index Model}

Since the Swedish economist Sten Malmquist put forward Malmquist index in 1953[15], Caves, etc.[16] first time used it for the calculation of productivity variability in 1982, and combining with DEA theory and method, technical efficiency and distance function can be measured through linear programming method, application of Malmquist productivity index (hereinafter referred to as the Malmquist index) had been rapidly developed. Malmquist index is defined on the basis of distance functions. In terms of a system, for multiple input variables set $X$ and multiple output variables set $Y$, if $t$ th stage production possibility set is expressed as $S^{t}=\{(X, Y) \mid$ on $t$ th stage, $X$ can produce $Y\}$, according to research literatures[17-18], the distance functions of the sth stage production activities $\left(x^{s}\right.$ and $\left.y^{s}\right)$ relative to output and input of the $t$ th stage production possibility set $S^{t}$ are defined respectively as (1) and (2).

$$
\begin{gathered}
D_{o}^{t}\left(x^{s}, y^{s}\right)=\inf \left\{\theta \mid x^{s}, y^{s} / \theta \in s^{t}\right\}=\left(\sup \left\{z \mid\left(x^{s}, z y^{s}\right) \in s^{t}\right\}\right)^{-1} \\
D_{i}^{t}\left(x^{s}, y^{s}\right)=\sup \left\{\lambda \mid\left(x^{s} / \lambda, y^{s}\right) \in s^{t}\right\}
\end{gathered}
$$

In (1) and (2), the subscript o and $\mathrm{i}$ mean that distance functions are defined based respectively on outputs and inputs. Based on outputs namely to maximize outputs under the condition that an assigned level of input is given. Based on inputs namely to minimize inputs under the condition that a pre-determined level of outputs is satisfied. According to the characteristics of system objects, we can choose one from (1) and (2).

The research[19] has shown, the distance functions from (1) and (2) respectively just are the reciprocal of optimal value of the $\mathrm{C}^{2} \mathrm{R}$ model under constant returns to scale or $\mathrm{BC}^{2}$ model under variable returns to scale in the DEA theory. Solving model of distance functions can be seen from (3) and (4). The research results provide the possibility for estimating efficiency variability.

Malmquist index is calculated by using the ratio of distance functions. According to the definition of Malmquist index[19], from $t$ th to $(t+1)$ th stage, Malmquist index of measuring the total factor productivity growth can be expressed as (5).

$$
\begin{aligned}
& C^{2} R\left\{\begin{aligned}
& \max \mathrm{z}_{c}=\left(D_{c}^{t}\left(x^{k, s}, y^{k, s}\right)\right)^{-1} \\
& \text { s.t. } \quad x_{n}^{k, s} \geq \sum_{k=1}^{K} \lambda^{k, t} x_{n}^{k, t}, \quad n=1, \ldots, N \\
& \mathrm{z}_{c} y_{m}^{k, s} \leq \sum_{k=1}^{K} \lambda^{k, t} y_{m}^{k, t}, \quad m=1, \ldots, M \\
& \lambda^{k, t} \geq 0, \quad k=1,2, \ldots, K
\end{aligned}\right. \\
& B C^{2}\left\{\begin{array}{c}
\max \mathrm{z}_{v}=\left(D_{v}^{t}\left(x^{k, s}, y^{k, s}\right)\right)^{-1} \\
\text { s.t. } x_{n}^{k, s} \geq \sum_{k=1}^{K} \lambda^{k, t} x_{n}^{k, t}, \quad n=1, \ldots, N \\
\mathrm{z}_{v} y_{m}^{k, s} \leq \sum_{\mathrm{k}=1}^{K} \lambda^{k, t} y_{m}^{k, t}, \quad m=1, \ldots, M \\
\lambda^{k, t} \geq 0, \quad k=1,2, \ldots, K
\end{array}\right. \\
& M\left(x^{t}, y^{t}, x^{t+1}, y^{t+1}\right)=\sqrt{\frac{D^{t}\left(x^{t+1}, y^{t+1}\right)}{D^{t}\left(x^{t}, y^{t}\right)} \times \frac{D^{t+1}\left(x^{t+1}, y^{t+1}\right)}{D^{t+1}\left(x^{t}, y^{t}\right)}}
\end{aligned}
$$

Distance functions in (5) were derived from the $C^{2} R$ model under the assumption of constant returns to scale. The value of Malmquist index was greater than 1 , which indicated that total factor productivity increased from $t$ th to $(t+1)$ th stage.

Empirical research[20] has indicated, Malmquist index can be further decomposed into the composite efficiency variability index and technical progress variability index under the assumption of constant returns to scale $\left(C^{2} R\right.$ model). When returns to scale changes $\left(\mathrm{BC}^{2}\right.$ model), the composite efficiency variability index can be further decomposed into pure technical efficiency index and scale efficiency index (see (6)).

$$
\begin{gathered}
M\left(x^{t}, y^{t}, x^{t+1}, y^{t+1}\right)=\frac{D_{V}^{t+1}\left(x^{t+1}, y^{t+1}\right)}{D_{V}^{t}\left(x^{t}, y^{t}\right)} \times \frac{D_{C}^{t+1}\left(x^{t+1}, y^{t+1}\right) / D_{V}^{t+1}\left(x^{t+1}, y^{t+1}\right)}{D_{C}^{t}\left(x^{t}, y^{t}\right) / D_{V}^{t}\left(x^{t}, y^{t}\right)} \times \\
\sqrt{\frac{D_{C}^{t}\left(x^{t}, y^{t}\right)}{D_{C}^{t+1}\left(x^{t}, y^{t}\right)} \times \frac{D_{C}^{t}\left(x^{t+1}, y^{t+1}\right)}{D_{C}^{t+1}\left(x^{t+1}, y^{t+1}\right)}}=\Delta \mathrm{Te} \times \Delta \mathrm{S} \times \Delta \mathrm{T}
\end{gathered}
$$

$\mathrm{D}$ with subscript $\mathrm{V}$ represents the distance functions are obtained under the assumption of variable returns to scale while D with subscript $C$ represents the distance functions are obtained under the assumption of constant returns to scale. $\Delta \mathrm{Te}$, $\Delta \mathrm{S}$ and $\Delta \mathrm{T}$ respectively represent pure technical efficiency variability index, scale efficiency variability index and technical progress variability index. Composite efficiency variability index represents the change of the system management level within two periods, and it reflects whether the decision-making unit is closer to the current production frontier to produce or not; Technical progress variability index represents the move of production frontier within two periods, and it reflects the technical innovation.

In this paper, Malmquist index may be taken as logistics system efficiency. In terms of supply logistics systems for automobile parts, standardization is a main mean of improving system efficiency, so when composite efficiency index of logistics standardization was took as a input variable, as a decomposition term of Malmquist index , composite efficiency variability index can be assumed as logistics standardization 
efficiency variability index ( $\triangle$ WBe $)$, that is, decomposition model of logistics standardization efficiency variability index is shown as (7).

$$
\Delta W B e=\frac{D_{V}^{t+1}\left(x^{t+1}, y^{t+1}\right)}{D_{V}^{t}\left(x^{t}, y^{t}\right)} \times \frac{D_{C}^{t+1}\left(x^{t+1}, y^{t+1}\right) / D_{V}^{t+1}\left(x^{t+1}, y^{t+1}\right)}{D_{C}^{t}\left(x^{t}, y^{t}\right) / D_{V}^{t}\left(x^{t}, y^{t}\right)}
$$

\section{B. Input/Output Indicator Selection and Data Processing}

According to characteristics of supply logistics systems for automobile parts, input and output indicators for measuring efficiency variability were shown as follows.

\section{1) Selection of input indicators}

a) Logistics standardization composite index and its measurement: As defined in this paper, the logistics standardization composite index is an indicator which compositely reflects the degree of logistics systems meeting the relevant logistics standards.

According to the framework of logistics standard system in Fig.2, the relevant logistics standards are indentified and determined, and the composite evaluation indicator system of logistics standardization is produced. (see Fig.3)

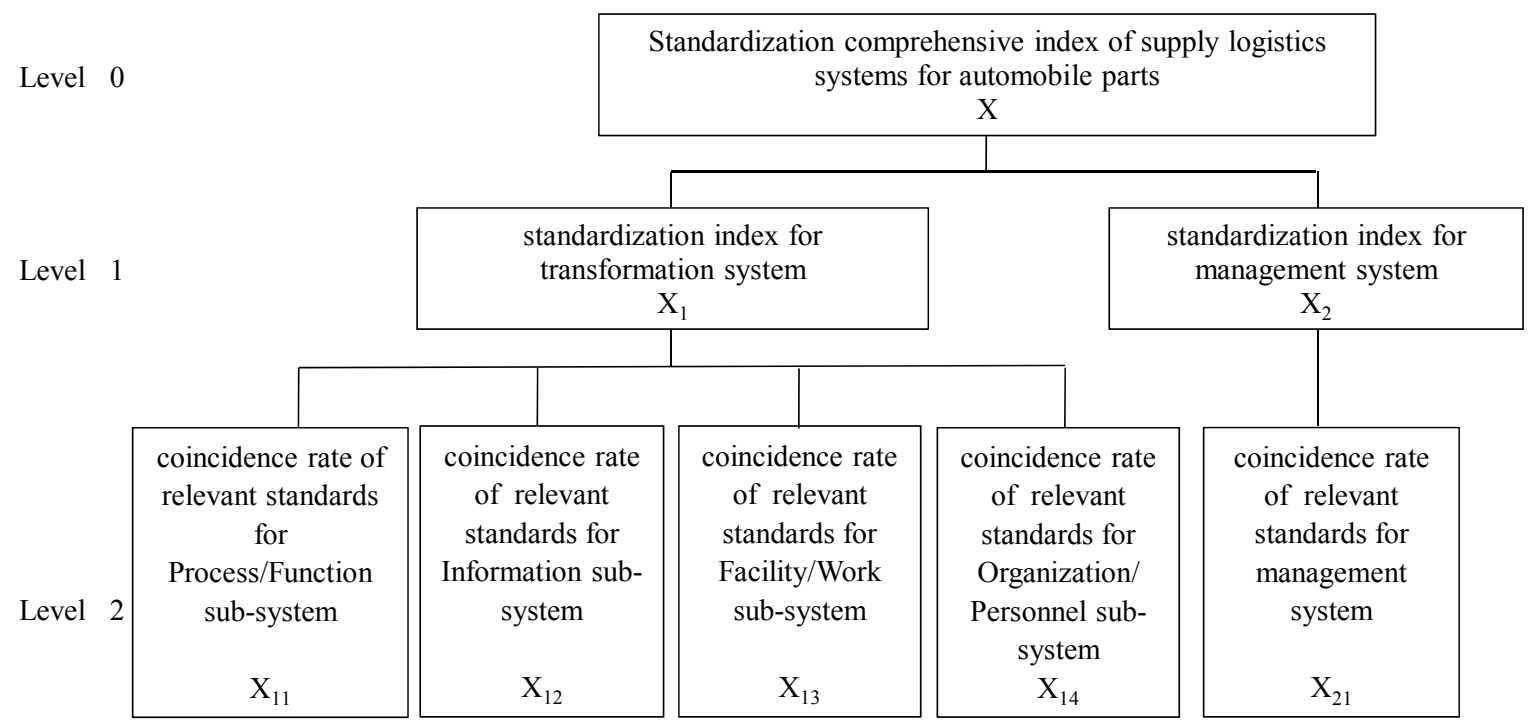

FIGURE III. STANDARDIZATION COMPOSITE EVALUATION INDICATOR SYSTEM OF SUPPLY LOGISTICS SYSTEMS FOR AUTOMOBILE PARTS

Based on construction of composite evaluation indicator system of logistics standardization, with the help of evaluation method of synergistic capacity in the literature[21], the standardization composite evaluation value of logistics systems was obtained. Firstly, the indicator weighting subset is determined by using analytic hierarchy process (AHP), then fuzzy evaluation weights of the underlying indicators are derived by using fuzzy theory, and standardization composite evaluation value of logistics systems was determined by using fuzzy composite method, which was taken as the logistics standardization composite index value.

b) Capital input indicator: Capital input is an important indicator for measuring development of a company or an organization. There are many kinds of measurement form for capital input. Generally, there are the total amount of capital formation, fixed capital input, alterable capital input and capital stock.

c) cLabor input indicator: Labor input can indirectly reflect the scale and development of logistics systems. There are many kinds of indicator for measuring labor input, including quantity of employment, labor time and labor intensity and labor remuneration, etc. Different measurement indicators are selected according to the characteristics of logistics systems for different companies or organizations.
2) Selection of output indicators: In terms of supply logistics systems of automobile parts, its main goal is to meet the production demand of parent factories. Therefore, customer (parent factories) satisfaction degree is a most important output indicator. Customer satisfaction degree is generally reflected by customer satisfaction degree index.

\section{CASE Study}

Currently services for supply logistics of auto parts in China are basically offered by the third party logistics enterprises. From the angle of problem research, this paper selected part supply logistics systems of 6 automobile assembly lines in China, which logistics services were provided by $\mathrm{W}$ logistics enterprise, as decision-making units to study. The six automobile assembly lines belong to different automobile models and brands, and the parts and suppliers of each assembly line are different, there are the certain gaps for their standardization degree of supply logistics systems and logistics system efficiency.

By means of the actual investigation for 6 supply logistics systems, on the basis of clearing the relevant logistics standards of varies systems and their respective promotion level, input and output data of each assembly line are analyzed and sorted out during the period of $2009 \sim 2014$. Considering the 
confidentiality, data for only one line was listed as shown in TABLE I.

Data relating to Malmquist index derived from using DEAP2.1 developed by Coelli $\mathrm{T} \mathbf{J}$ were shown in TABLE II and TABLE III.

TABLE I. DATA OF INPUT AND OUTPUT FOR LINE 1

\begin{tabular}{c|c|c|l|c}
\hline \multirow{2}{*}{$\begin{array}{l}\text { Indicators } \\
\text { Year }\end{array}$} & \multicolumn{3}{|c|}{ Input indicators } & $\begin{array}{l}\text { Output } \\
\text { indicator }\end{array}$ \\
\cline { 2 - 5 } & $\begin{array}{l}\text { Logistics } \\
\text { standardizat } \\
\text { ion } \\
\text { composite } \\
\text { index }\end{array}$ & $\begin{array}{c}\text { Capital } \\
\text { input } \\
\text { ten } \\
\text { thousan } \\
\text { d yuan) }\end{array}$ & $\begin{array}{l}\text { Labor } \\
\text { input } \\
\text { (persons } \\
\text { ) }\end{array}$ & $\begin{array}{c}\text { Customer } \\
\text { satisfaction } \\
\text { degree index }\end{array}$ \\
\hline 2009 & 0.8452 & 3682 & 995 & $89.10 \%$ \\
\hline 2010 & 0.8628 & 3920 & 1056 & $88.90 \%$ \\
\hline 2011 & 0.8575 & 4307 & 1146 & $89.00 \%$ \\
\hline 2012 & 0.8633 & 4870 & 1203 & $89.00 \%$ \\
\hline 2013 & 0.8696 & 5081 & 1225 & $89.10 \%$ \\
\hline 2014 & 0.8722 & 5300 & 1236 & $90.20 \%$ \\
\hline
\end{tabular}

Data in TABLE II showed, for No.1 and No.2 assembly lines, the average Malmquist index values were greater than 1, and the logistics standardization efficiency variability index values were also greater than 1 , but the technical progress variability index values were less than 1 , which reflected technology have been tended to be stable in recent years, not much improved, while the standardization efficiency has been growing, and affecting the system efficiency.

\section{TABLE II. AVERAGE VALUE OF EACH SUPPLY LOGISTICS SYSTEM} IN 2009 2014

\begin{tabular}{c|c|c|c|c|c}
\hline $\begin{array}{c}\text { Prod } \\
\text { uctio } \\
\mathrm{n} \\
\text { line }\end{array}$ & $\begin{array}{c}\text { Pure } \\
\text { technical } \\
\text { efficiency } \\
\text { variability } \\
\text { index } \\
(\Delta \mathrm{Te})\end{array}$ & $\begin{array}{c}\text { Scale } \\
\text { efficiency } \\
\text { variability } \\
\text { index } \\
(\Delta \mathrm{S})\end{array}$ & $\begin{array}{c}\text { Logistics } \\
\text { standardizat } \\
\text { ion } \\
\text { efficiency } \\
\text { variability } \\
\text { index } \\
(\Delta \mathrm{WBe})\end{array}$ & $\begin{array}{c}\text { Technical } \\
\text { progress } \\
\text { variabilit } \\
\mathrm{y} \text { index } \\
(\Delta \mathrm{T})\end{array}$ & $\begin{array}{c}\text { Malm } \\
\text { quist } \\
\text { Index } \\
(\mathrm{M})\end{array}$ \\
\hline No.1 & 1 & 1.048 & 1.048 & 0.969 & 1.016 \\
\hline No.2 & 1.012 & 1.023 & 1.023 & 0.983 & 1.006 \\
\hline No.3 & 0.922 & 1.002 & 0.994 & 1.004 & 0.988 \\
\hline No.4 & 1.007 & 1 & 1.007 & 1.004 & 1.011 \\
\hline No.5 & 0.996 & 0.999 & 0.995 & 0.978 & 0.973 \\
\hline No.6 & 1 & 0.996 & 0.996 & 0.987 & 0.983 \\
\hline
\end{tabular}

Actual investigation results showed, suppliers for No.1, No. 2 and No.4 assembly lines mainly came from abroad, not only the production scale, the labor input and material resource input were large, but also abroad suppliers were ahead of domestic suppliers in terms of standardization, particularly information system that was unified with the parent factories, which provided effective guarantee for the delivering parts to warehouse, positioning storage, First-In-First-Out and other logistics activities.

In contrast, for No.5 and No.6 assembly lines in TABLE II, the average Malmquist index values were less than 1, the technical progress index values and the logistics standardization efficiency variability index values were also less than 1, which reflected there was no improvement in the management and technology, even there was a downward trend.

TABLE III. ANNUALLY AVERAGE VALUES OF SIX ASSEMBLY LINES

\begin{tabular}{l|c|c|c|c|c}
\hline year & $\begin{array}{c}\text { Pure } \\
\text { technical } \\
\text { efficienc } \\
\mathrm{y} \\
\text { variabilit } \\
\text { y index } \\
(\Delta \mathrm{Te})\end{array}$ & $\begin{array}{c}\text { Scale } \\
\text { efficien } \\
\text { cy } \\
\text { variabili } \\
\text { ty index } \\
(\Delta \mathrm{S})\end{array}$ & $\begin{array}{c}\text { Logistics } \\
\text { standardizat } \\
\text { ion } \\
\text { efficiency } \\
\text { variability } \\
\text { index } \\
(\Delta \mathrm{WBe})\end{array}$ & $\begin{array}{c}\text { Technic } \\
\text { al } \\
\text { progress } \\
\text { variabili } \\
\text { ty index } \\
(\Delta \mathrm{T})\end{array}$ & $\begin{array}{c}\text { Malmquis } \\
\mathrm{t}\end{array}$ \\
\hline $\begin{array}{l}\text { Index } \\
(\mathrm{M})\end{array}$ \\
\hline $\begin{array}{l}2009 \sim \\
2010 \sim\end{array}$ & 0.996 & 0.973 & 0.969 & 1.064 & 1.031 \\
\hline $\begin{array}{l}2011 \\
2011 \sim\end{array}$ & 0.994 & 0.994 & 0.986 & 1.064 & 1.048 \\
\hline $\begin{array}{l}2012 \sim \\
2013\end{array}$ & 1.043 & 1.032 & 1.077 & 0.987 & 1.063 \\
\hline $\begin{array}{l}2013 \sim \\
2014\end{array}$ & 1.059 & 1.018 & 1.079 & 1.006 & 1.085 \\
\hline $\begin{array}{l}\text { averag } \\
\mathrm{e}\end{array}$ & 0.973 & 0.987 & 0.963 & 1.100 & 1.040 \\
\hline
\end{tabular}

Actual investigation found that suppliers for No.3, No.5 and No.6 assembly lines mainly came from domestic, and the domestic suppliers were scattered, not only the scale was relatively small, and management mechanism in the logistics activities of transportation and storage was not perfect, but also standardization degree was lower, especially the information system was not unified with the parent factories, greatly hindered the improvement for operation efficiency of supply logistics systems for automobile parts.

Data in TABLE III also showed that in 2009 2014, although there were logistics standardization efficiency variability index values been greater than 1 , the its average value was less than 1 . And almost all technical progress variability index values were greater than 1 , the average value was also greater than 1 . The above reflected that in the recent five years, the promoting force for the logistics enterprise mainly was technical progress, and the logistics standardization has not become the main competitiveness of logistics enterprises. But by data comparison, we can find the logistics standardization efficiency variability index values remained rising, and in the past two years, the values were greater than 1 , which explained that influence the logistics standardization produced on the logistics system efficiency was bigger and bigger.

Actual investigation results showed that, in recent years, W logistics enterprise has been committed to improve the management system and to increase the coincidence rate of relevant standards and customer satisfaction degree year by year, and the advanced information system was introduced for management in the warehousing and distribution, including the 
acceptance of receiving standards, storage standards, replenishment standards, dispatch standards and delivery standards, etc, and the effect of which will gradually be reflected as the improvement of logistics system efficiency, and will further promote long-term development of logistics enterprises and even logistics industries.

In a word, the data obtained by Malmquist index model, the logistics standardization efficiency variability index model and technical progress variability index model reflected the actual operation status of six supply logistics systems.

\section{CONCLUSION}

The logistics globalization promoted logistics standardization. Requiring coordination for logistics activities brought out systematic requirements of logistics standardization. Supply logistics systems of automobile parts provided a possibility for a small study on the logistics standardization effect.

Logistics standard systems that were taken from logistics systems and serviced for logistics systems needed to be in conformity with the logistics system architecture. "Push" and "pull" logistics standardization modes provided suitable and feasible methods for the development and promotion of effective logistics standards. Definition and measurement method of logistics standardization composite index made it possible for composite measurement of logistics standardization degree.

Malmquist index theory and method based on DEA provided a theoretical basis for research on the correlation between logistics standardization efficiency and logistics system efficiency. It is the choice of decision-making units and input/output indicators that are critical to effective application of the method. Through the selecting and applying of the input/output indicators such as logistics standardization composite index, capital input, labor input and customer satisfaction degree index, etc, effectiveness of Malmquist index of supply logistics systems for automobile parts and logistics standardization efficiency model was verified in this paper.

Although due to weakness of China's logistics standardization work and the limitation of collecting the data, etc., analysis depth and research conclusions were still preliminary, the research idea and method provided a new methodology for measuring the logistics standardization effect and promoting the logistics standardization.

\section{ACKNOWLEDGMENT}

This work was supported by the National Natural Science Foundation of China (71271035).

\section{REFERENCE}

[1] Wang Huixin. Construction and implementation strategy research for the auto industry third-party logistics standardization - taking MS logistics in Chongqing as an example[J]. Logistics technology, vol.33, no.12, pp. 124-128, 2014

[2] Meng Fanye. Research on Cost Control of Auto Parts Milkrun project of Jingbei Motor Company[D]. Changchun: Jilin University Press, 2014

[3] Jahre, M. and Fabbe-Costes, N. Adaptation and adaptability in logistics networks[J]. International Journal of Logistics: Research and Applications, vol.8, no.2, pp.143-57, 2005.
[4] Nathalie Fabbe-Costes, Marianne Jahre, Aurélien Rouquet. Interacting Standards: a Basic Element in Logistics Networks [J]. International Journal of Physical Distribution \& Logistics Management, 2006, vol.36, no.2, pp.93-111, 2006.

[5] Ciliberti, Francesco, Pontrandolfo, Pierpaolo, Scozzi, Barbara. Logistics social responsibility: Standard adoption and practices in Italian companies [J]. International Journal of Production Economics, vol.113, no.1, pp.88-106, 2008.

[6] Huishu Piao, Hengfei Wang, Shuangquan Chu, "Modularity design of logistics systems", in Proceedings of the 2010 IEEE International Conference on Automation and Logistics, pp.183-188, 2010.

[7] Wu Yanfeng. Study on Establishment of Logistics Standard System of China-Asean Free Trade Zone[J]. Logistics Technology, vol.32, no.5, pp.77-81, 2014.

[8] Garland Chow, Trevor D. Heaver, Lennart E. Henriksson. Logistics Performance: Definition and Measurement[J]. International Journal of Physical Distribution \& Logistics Management, vol.24, no.1, pp.17-28, 1994.

[9] Michael Tracey. The Importance of Logistics Efficiency to Customer Service and Firm Performance[J]. The International Journal of Logistics Management, vol.9, no.2, pp.65-81, 1998.

[10] Gengui Zhou, Hokey Min, Chao Xu, Zhenyu Cao. Evaluating the comparative efficiency of Chinese third-party logistics providers using data envelopment analysis [J]. International Journal of Physical Distribution \& Logistics Management, vol.38, no.4, pp. 262-279, 2008.

[11] R. Leitner, F. Meizer, M. Prochazka, W. Sihn. Structural concepts for horizontal cooperation to increase efficiency in logistics[J]. CIRP Journal of Manufacturing Science and Technology, vol.4, no.3, pp.332-337, 2011.

[12] Tian Gang. Research on technical efficiency, technical progress and regional disparity of China's logistics industry [D]. Nanjing : Nanjing University of Aeronautics and Astronautics Press, 2010.

[13] Hokey Min, Seong Jong Joo . Benchmarking the operational efficiency of third party logistics providers using data envelopment analysis[J]. Supply Chain Management: An International Journal, vol.11, no.3, pp. 259-265, 2006.

[14] Amer Hamdan_, K.J. (Jamie) Rogers. Evaluating the efficiency of 3PL logistics operations[J]. Intenational Journal of Production Economics, no.113, pp.235-244, 2008.

[15] MALMQUIST STEN. Index numbers and indifference surffaces[J]. Tra - bajos de Estadistica, vol.1953, no.4, pp.209-232, 1953.

[16] CAVES DW, CHRISTENSEN LR, DIEWERT WE. The economic theory of index numbers and the measurement of input, output and productivity [J]. Econometrica, vol.50, no.6, pp.1393-1414, 1982.

[17] Y. H. Chung, R. Fa“re and S. Grosskopf. Productivity and Undesirable Outputs: A Directional Distance Function Approach[J]. Journal of Environmental Management, vol.1997, no.51, pp.229-240, 1997.

[18] Atakelty Hailu, Terrence S. Veeman. Environmentally Sensitive Productivity Analysis of the Canadian Pulp and Paper Industry, 19591994: An Input Distance Function Approach[J]. Journal of Environmental Economics and Management, no.40, pp.251-274, 2000.

[19] Zhang Xiangsun, Gui Binwei. The analysis of total factor productivity in china: a review and application of Malmquist index approach[J].Quantitative \&Technical Economics, no.6, pp.111-122, 2008.

[20] Yu Jian, Li Yanwei. Management efficiency technique upgrade and productivity improvement based on comparison research of Chinese and American airline industry[J]. Journal of China civil Aviation University, vol.26, no.6, pp.42-47, 2008.

[21] Piao Huishu, Liu Huibin, Zhang Bing. A composite assessment method of container multi-modal transportation synergistic capacity $[\mathrm{J}]$. Navigation of China, vol.36, no.4, pp.125-129, 2013. 